Esquema de

Lucio Costa

Un milagro, mucha

arquitectura y un último espejismo 


\section{Esquema de Lucio Costa}

Un milagro, mucha arquitectura y un último espejismo

\section{9}

ARTÍCULO EN LA REVISTA

Block 
Categorías: Filosofía; Política; Estética; Arquitectura y Ciudades; Artes plásticas; Crítica de cultura y trayectorias. Cada categoría adopta un color específico en la portada del libro electrónico.

\section{Subcolecciones:}

Libros electrónicos: libros, capítulos, prefacios, artículos y entrevistas (en formatos PDF, EPUB y MOBI / Kindle) - con obras en portugués, inglés, español, italiano y francés.

Documentos: artículos de periódicos, fotografías y documentos históricos (en formato PDF y JPEG)

Medios: Vídeos o audios de conferencias, clases y debates (en formatos MP3 y MP4) asociados a un canal de YouTube de la colección.

Coordinación editorial: Pedro Fiori Arantes

Proyecto gráfico: Paula Astiz

Datos Internacionales de Catalogación en Publicación (CIP)

Arantes, Otília Beatriz Fiori, 1940

Esquema de Lúcio Costa [recurso electrónico] : un milagro, mucha

arquitectura y un último espejismo / Otília Beatriz Fiori Arantes

[tradución Adriana Rodrígues Pérsico]. -- São Paulo : [s.n], 2021.

ePUB. - (Colección sentimento da dialética / ccoordinación Pedro Fiori Arantes)

\section{ISBN 978-65-00-32347-4}

1. Costa, Lúcio, 1902-1998. 2. Arquitetura moderna - Séc. XX. 3 . Arquitetura - Filosofia. 4. Arquitetura e sociedade. I. Arantes, Pedro Fiori, 1974-. Il. Titulo. III. Serie.

CDD 720.1

Elaborado por Cristiane de Melo Shirayama - CRB 8/7610

DOI: https://doi.org/10.34024/9786500323474

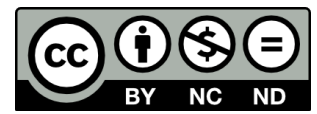

Esta obra tiene licencia Creative Commons internacional 4.0

http://creativecommons.org/licenses/by-nc-nd/4.0/

Publicado originalmente en:

Revista Block n.4, 1999, Universidad Torcuato di Tella, Buenos Aires, pp. 42-53.

\section{Sentimento da Dialética}

UN ENCUENTRO CON LA OBRA DE OTÍLIA Y PAULO ARANTES

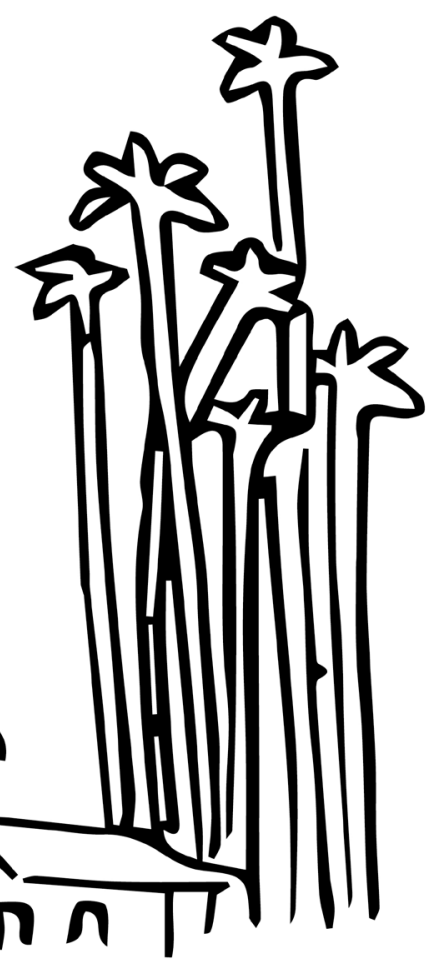




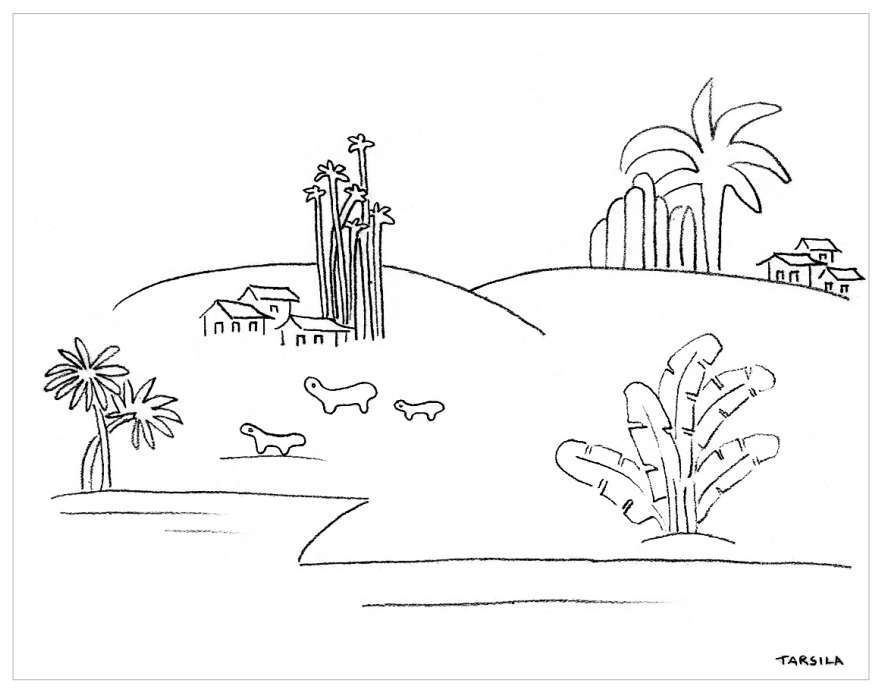

Tarsila do Amaral. Paisaje antropofágico - I, 1929 c - lápiz sobre papel, $18,0 \times 22,9 \mathrm{~cm}$. Colección Mário de Andrade.

Colección de Artes Visuales del Instituto de Estudos Brasileiros USP. Reproducción amablemente proporcionada por la familia y el IEB USP.

El nuevo tiempo del mundo exige a los intelectuales responsabilidades que les son intrínsecas: hacer que el poder de las ideas forme parte del movimiento de comprensión y transformación del mundo. Los filósofos Otília Beatriz Fiori Arantes y Paulo Eduardo Arantes llevan más de 50 años desarrollando juntos la tarea de la crítica como intelectuales públicos activos, moviéndose entre diferentes áreas de las humanidades y la cultura, en diferentes públicos y espacios de formación. La colección Sentimento da Dialética recopila y edita en libros digitales gratuitos su producción intelectual, es un lugar de encuentro de la obra de Otília y Paulo Arantes y reafirma el sentido colectivo de la misma. Es un encuentro de su obra con un público cada vez más amplio, plural y popular, formado por estudiantes, nuevos intelectuales y activistas brasileños. Es también un encuentro de su obra con el movimiento contemporáneo en defensa del conocimiento libre y desmercantilizado, en la producción de lo común y de otro mundo posible. ctivistas brasileños. Es también un encuentro de su obra con el movimiento contemporáneo en defensa del conocimiento libre y desmercantilizado, en la producción de lo común y de otro mundo posible. 
ESQUEMA DE LUCIO COSTA

Un milagro, mucha arquitectura y un último espejismo 


\section{ESQUEMA DE LUCIO COSTA}

\section{Un milagro, mucha arquitectura y un último espejismo ${ }^{1}$}

\section{Moderno por azar}

¿Habrá surgido por milagro la Arquitectura Moderna Brasileña? Por lo menos, ésta parece ser la opinión de Lucio Costa, al adoptar, en su antológico ensayo de 1951, el título: "Mucha construcción, alguna arquitectura y un milagro". ${ }^{2}$ Antes de desmenuzar sus razones, es preciso reconocer una vez más que, como en todos los países periféricos y de tradiciones culturales no sedimentadas, los asomos de modernización parecen ocurrir por obra del azar. Y, para reforzar esta casi certeza en cuanto al carácter fortuito de ese hecho histórico, cuando se le preguntaba sobre cuándo y cómo había adherido a la Arquitectura Moderna, Lucio Costa decía invariablemente que la había descubierto muy tardey, aparentemente, bajo circunstancias que podrían no haber ocurrido, agregando que de no haber sido así, aquélla, probablemente, no habría existido. Es evidente que su conocida discreción no le permitía

1. Publicado originalmente en la Revista Block n.4, 1999, Universidad Torcuato di Tella, pp. 42-53.

2. Todas las citas de Lucio Costa son de Registro de uma vivência. UNB/Empresa das Artes, 1995 - única compilación autorizada por el Arquitecto. 
hablar únicamente de sí mismo sino de una serie de coincidencias que terminaron por poner en su camino, por ejemplo, a Le Corbusier y Oscar Niemeyer; sin ello, el referido milagro no habría sucedido. Por lo tanto, que haya una combinación de factores subjetivos y objetivos -más o menos rutinarios cuando se trata de culturas orgánicas aunque en general bastante accidentales en un medio en principio adverso a las grandes maniobras de la historia del espíritu-depende, como no podría dejar de ser, de casualidades felices o arrobos que pasan por geniales.

Sólo dos ejemplos de "formaciones" imprevisibles en el Brasil: si no se hubiera dado la coincidencia -hace casi ciento cincuenta años - de la ida a París de nuestro joven (pre)romántico Gonçalves de Magalhães cuando estaba allá el crítico y escritor portugués Almeida Garret, no habría editado, con un grupo de jóvenes escritores brasileños, una revista de cuño nítidamente nacional, que lleva el nombre sugestivo de "Niterói", dando así inicio a nuestro romanticismo, y con él, forma a una literatura que, aunque todavía fuera de imitación, ya iba adquiriendo rasgos locales. Sin ese encuentro casual, esto tal vez nunca habría ocurrido o habría quedado hibernando a la espera de una nueva casualidad. Transcurrido casi un siglo, otro acontecimiento semejante: nuestros "modernistas" de la Semana del 22 - nuevamente en París y con el objetivo de desprovincializarse- descubrieron, por casualidad, el Brasil desde lo alto de un atelier en la plaza Clichy (una boutade que se hizo famosa por su evidente fondo de verdad, el eterno falso fondo de las revelaciones nacionales más auténticas) al rever el arte primitivo expuesto en lugar destacado en vidrieras y galerías de arte, después de que las vanguardias estéticas lo hubieran reinventado. Respondiendo al llamado del "Nuevo Orden", mientras
Tarsila do Amaral seguía las lecciones del maestro Lhote, esos jóvenes invertían el futurismo provinciano del primer momento brasileño modernista y reencontraban, en París, la veta local: "Pau-Brasil". O sea, descubrían que nuestro "primitivismo" (nacional) era cubista (internacional). En suma, ¡nuestra vocación moderna era un ready-made hallado en Europa!

Sin saberlo, en la misma época (1926-1927) circulaba por Parísy Roma el que sería, sin duda, el inventor de nuestra Arquitectura Moderna-Lucio Costa- que "por motivos sentimentales insolubles" (como confesó más tarde) había resuelto viajar interrumpiendo sus poco inspiradas actividades de arquitecto neocolonial o ecléctico-académico. Se puso entonces a estudiar la arquitectura de Europa (que no le era extraña después de haber vivido allí tantos años) pero sin prestar atención a lo que estaba surgiendo de nuevo, a tal punto que en el viaje de vuelta, cuando participaba de un juego un tanto pueril, en el que había que adivinar, bajo pena de ser ahorcado, la palabra a partir de la letra inicial, perdió porque no descubrió que la L era de Le Corbusier. El episodio hizo que este nombre se le grabara definitivamente. Anécdota que no se privaba de contar para demostrar cuán ajeno a las nuevas tendencias estaba en esa época o quizás, para sugerir maliciosamente el secreto de esta otra devinette: haber tomado el hábito de firmar sólo con las iniciales L.C. para el resto de su vida.

Desmenucemos aún otras circunstancias ocasionales: como en el período del viaje a Europa había contraído una dolencia pulmonar, fue a curarse a Minas. Allí volvió a tomar contacto y a profundizar sus conocimientos de nuestra arquitectura del tiempo de la Colonia al punto que se dio cuenta de que el neocolonial al que adhiriera algunos 
años antes estaba equivocado: "lamentable mezcla de arquitectura religiosa y civil, de pormenores inherentes a épocas y técnicas diferentes, cuando habría sido tan fácil aprovechar la experiencia tradicional en lo que tiene de válido para hoy y para siempre" . La verdad es que el viaje a Europa y luego a Minas, promediando los años 20, causaron una especie de cortocircuito en la trayectoria de nuestro arquitecto franco-brasileño, prenunciando, de algún modo, lo que pasaría. Cuenta él que un poco antes de 1930 vio reproducida en una revista -que no era siquiera una revista especializada, Para todos (como por otra parte, el mismo nombre sugiere) - una casa de Warchawchick en San Pablo bautizada como "modernista" porque allí se hacía una exposición de los artistas de la Semana del 22 y como se le solicitó proyectar una casa para una señora de la alta burguesía, resolvió hacer un proyecto "contemporáneo" que, obviamente, desagradó al cliente: "le vengo a pedir un carruaje y el señor quiere imponerme un automóvil!" A este gesto intempestivo no siguieron otros, con excepción de la invitación para dirigir la Escuela de Bellas Artes. Nuevamente Lucio Costa narra el hecho como si no hubiera entendido lo que pasaba: "con la revolución del 30, uno de los primeros actos de gobierno fue la nominación de los nuevos directores del área de Educación y Cultura (...) Tomado de sorpresa, recibí en Correias un mensaje de Rodrigo M.F. de Andrade, al que todavía no conocía, pidiendo que compareciera al Ministerio entonces instalado en el edificio de la Asamblea, en la Plaza Floriano. Me vi así, de la noche a la mañana, frente a la tarea de organizar la enseñanza de las llamadas Bellas Artes”. Aunque sabía que su misión era la de modernizar la escuela, advierte en una entrevista de la época: "Que venga de adentro para afuera y no de afuera para adentro, pues el falso modernismo es mil veces peor que todos los academicismos". Todo hace crer que no se sentía a la altura de dicha tarea que evalúa, en su nota autobiográfica, como una "intervención fracasada" porque habría desembocado "en el desmantelamiento de lo que había sin dejar nada en su lugar". Sin embargo, concede, "tuvo un remate feliz con la realización del extraordinario Salón del 31" donde por la primera vez fueron admitidos el arte y la arquitectura no académicos. Los efectos son innegables y, lo más importante, al final, el cambio había ocurrido.

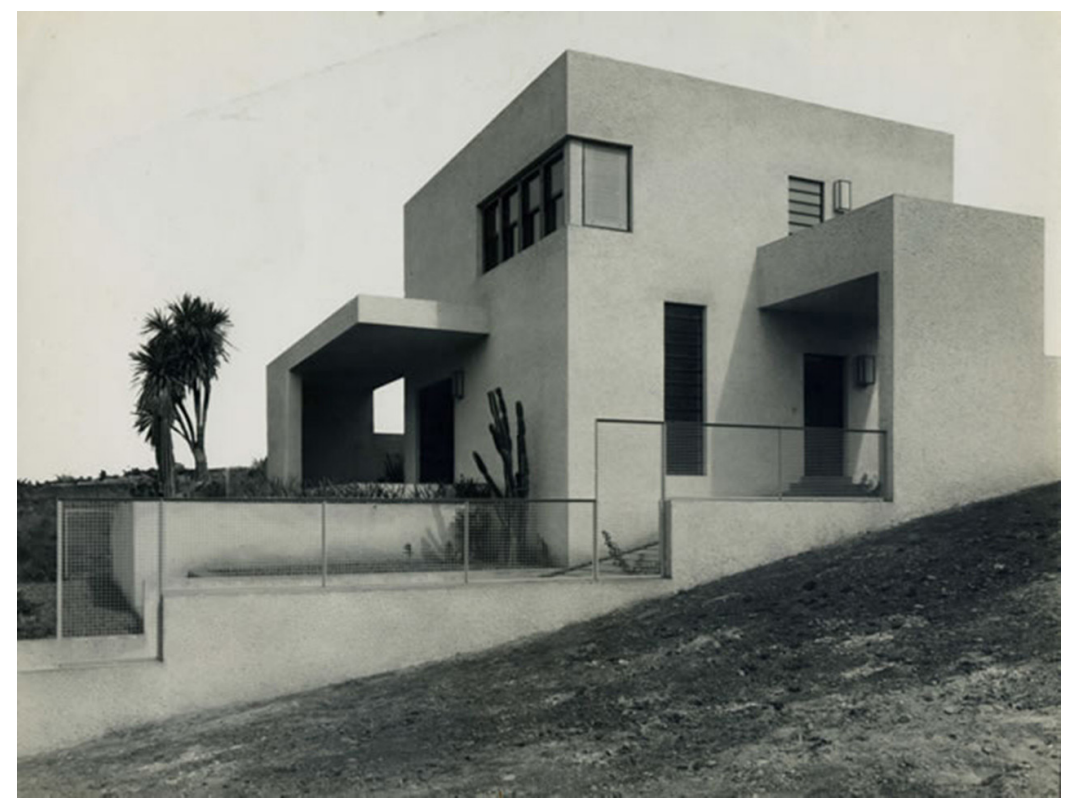

Gregori Warchavchik, Casa Modernista de la rua Itápolis, São Paulo, 1930

Aparentemente, estas casualidades habían hecho de Lucio Costa un moderno. No obstante ya estaban dadas ahí las premisas de lo que, en su arquitectura o la nues- 
tra, retomaba (sin querer) el lugar común modernista, como lo habia formulado Mário de Andrade ${ }^{3}$ : es necesario "tradicionalizar" nuestro pasado, es decir, al Brasil (huelga aclarar que se trata de tradición sin tradicionalismo). Especie de antídoto contra la perturbación de la que hablaba Joaquim Nabuco: el malestar del exilio en su propia patria. Tradicionalizar sería ante todo referir el pasado al presente, vivirlo y no revivirlo (no es revival, ni siquiera neocolonial); por ejemplo, reconstruir el pasado vivo que pesa en cada uno de los gestos de los contemporáneos. En mi opinión, aquí aparece uno de los embriones de lo que se podría llamar efecto retroactivo del proceso de formación que busca completarse por influjo moderno necesariamente externo y por ello mismo preponderante, como veremos enseguida. Primera versión de la futura "liberación localista de lo reprimido" ${ }^{*}$ de la que hablará nuestro gran crítico literario, Antonio Candido. O mejor, en el lenguaje también psicoanalítico de otro precursor no menos ilustre, Gilberto Freyre, que en 1926 exalta la necesidad de "destabuizar" o destapar el Brasil encubierto por la mentira oficial, postizo. En fin, una cura psicoanalítica que acabara con todas las coartadas (por ejemplo, la indianista, mientras se revela el Brasil real, "negro").

Arriesgando algunas hipótesis - puesto que todavía no reconstituimos todas las piezas del rompecabezas en el origen del referido "milagro" - también será posible hablar de esta "liberación" (tradicionalizante), o "destape",

3. Al hablar de "modernismo", estoy utilizando siempre la expresión en su acepción brasileña, que designa al movimiento de vanguardia que se originó en San Pablo en 1922 bajo el liderazgo de, entre otros, Mário y Oswald de Andrade.

4. En portugués: desrecalque (lo contrario de represión), lo mismo que défoulement en francés. (N.T.) en el sentido psicoanalítico-cultural del término, aplicado a la Arquitectura Moderna Brasileña. Es decir, en la medida en que tomemos la arquitectura ecléctico-historicista burguesa como un síntoma neurótico encubridor del país arquitectónico real, podremos quitar el barniz y arrojar luz sobre la sinceridad de la estructura construida. La terapia es también moderna e importada; la honestidad constructiva de los modernos, blanca y aséptica como la ética productiva del trabajo que ella tenía en su centro. Con la mediación del "abrasileñamiento" del programa corbusiano que conocemos -aunque no todavía en el desarrollo de esta exposición- Lucio Costa reconoció simplemente, en el esqueleto moderno aliviado del abigarramiento de los estilos, un parentesco con la antigua sabiduría constructiva de la arquitectura civil colonial. Una variante posible de aquel efecto retroactivo del proceso de formación, en este caso, de nuestra moderna arquitectura. Pero todavía no presentamos tal proceso.

Después de esta aproximación y antes de continuar, se hace necesaria una objeción que evite la inadecuación de la amalgama. En verdad, Lucio Costa nunca se reconoció en el Movimiento Modernista, al menos en el alto modernismo de los años 20 y todo lo que derivó de él y continúa actuando en la moderna tradición brasileña reciente. Por otra parte, como vimos, mientras los modernistas del período heroico alimentaban la utopía de un rumbo civilizatorio alternativo que desarrollase el encanto preburgués del pueblo menudo - que la colonización segregara- en términos de la cultura artística y técnica más avanzada, el arquitecto carioca que sería la personificación más acabada del Movimiento Moderno en Arquitectura en el Brasil, se debatía aún con equívocos como el de la imitación neocolonial. En consecuencia, moderno sin ser moder- 
nista, Lucio Costa tomó el modernismo directamente, en un período constructivo-iluminista de organización institucional de la cultura y sus correlatos. Esto provocó una curiosa inversión: es como si nuestro Arquitecto se hubiera descubierto moderno después de descubrirse brasileño; pero ello fue posible sólo porque otros (justamente los modernistas con los que establecía una cordialísima distancia) ya habían recorrido antes, en su lugar, el camino en sentido inverso, o sea, habían releído modernamente nuestro pasado. No hay que olvidar que, si por un lado, el no tan joven Lucio se declaró moderno un poco tarde y aparentemente motivado por el redescubrimiento de Brasil, alegó primero las "Razones de la nueva arquitectura" (34/35) para repertoriar — algunos años más tarde y como expert en patrimonio- la "Documentación necesaria" (37/38) que haría de ella, a pesar de sus rasgos internacionales, "una manifestación de carácter local". Un pasado, entonces, revisitado desde un punto de vista moderno ya constituido. Al mismo tiempo, al llegar post festum, ausente ya la carga satírica-negativa de la primera hora, se hacía cada vez más difícil imaginar el orden social alternativo al que la nueva técnica debería, en principio, pertenecer. Ventajas y desventajas de esta entrada tardía en materia: por ejemplo, el beneficio de la mencionada "liberación localista" ocurrida en los años 20, pero ya rutinaria; asimismo la sustitución del mito modernista del país no oficial por el mito de la Nación Moderna pero, del lado de las desventajas, bajo el patrocinio del Estado.

Tal vez se pueda decir a modo de conclusión de esta digresión preliminar sobre el carácter "nacional" de la Arquitectura Moderna Brasileña concebida por Lucio Costa: en materia de Movimiento Moderno, la originalidad de la contribución brasileña consiste precisamente en este hecho singular, que en nuestro país los modernos son los primeros (más autorizados y armados) que se empeñan en la recuperación y preservación de la arquitectura tradicional; las mismas personas que proponían una renovación moderna reclamaban una vuelta de lo antiguo. Son, de esta manera, ante todo modernos y no nostálgicos del pasado (o sea, académicos) y, justamente por ser modernos son los primeros en vincularse -en otro registro- con la tradición.

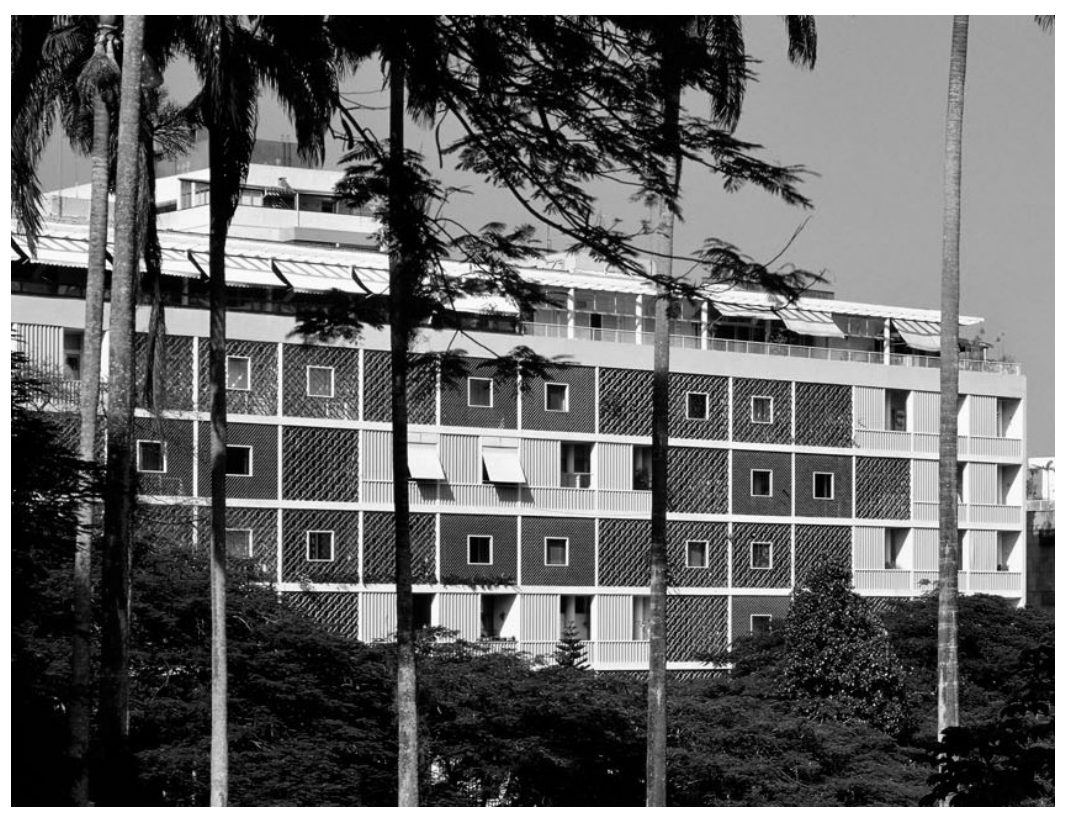

Lucio Costa, Conjunto residencial Parque Guinle, Rio de Janeiro, 1954

No es cuestión de tomar posición a favor o en contra de este "disparate". Se trata, evidentemente, de una configuración objetiva. La clave del enigma está en descifrar la 
lógica de ese dispositivo material que debe ser identificado y que no se agota simplemente en desenmascar o acatar el ideario sostenido, el abrasileñamiento, exitoso o no, de la arquitectura moderna.

Por otra parte, si atacamos directamente el problema desde la raíz estructural mencionada, debemos destacar que la alianza entre moderno y tradicional es la fórmula histórica del aspecto original, rigurosamente no-clásico, que adoptó en Brasil el pasaje entre el antiguo sistema colonial-mercantil y el nuevo mundo del capital industrial. Esta alianza es la matriz práctica que impulsa la dinámica heterodoxa de nuestra formación social, económica y cultural que se enfrenta con la norma europea de transición entre el feudalismo y el capitalismo. Aquí no existió eso, nacimos "modernos" (no feudales) y "coloniales", bajo la égida del capitalismo comercial en expansión. De ahí la esclavitud, el monocultivo, producción a un mismo tiempo patriarcal y mercantil, apuntados al mercado internacional. Las mil formas antagónicas y conciliatorias de convivencia entre capitalismo y esclavitud -el Brasil burgués y el país colonial- están en el origen del "esquema" de Lucio Costa, un esquema, por esa razón, de compromiso con el Estado, con lo que será el moderno Estado Nuevo al que sucede el Estado Desarrollista del segundo Getúlio Vargas y Juscelino Kubitschek. Pero esto es sólo el suelo histórico más remoto. Ser fiel al patrimonio histórico y a la tradición artística local porque se es moderno y no a pesar de ello, es lo mismo -con otras cien mil mediaciones - que modernizarse reponiendo o refuncionalizando el "atraso" heredado o restaurado. En pocas palabras, lo moderno crece y se alimenta reproduciendo lo atrasado; de obstáculo y residuo, el arcaísmo pasa a instrumento de la opresión más moderna. El Bra- sil es así hasta hoy: un paso ultramoderno de inserción internacional (subordinada) dado por la misma coalición conservadora que se consolidó en los compromisos del 30. Modernización conservadora, como el nombre señala, quiere decir reestructuración productiva con inequidad social, y esto es así tanto en la nueva coyuntura como en la anterior.

Sin embargo el dinamismo dual de la vida nacional no se resume en dos o tres modalidades artísticas de transposición estética, polémica o apologética. Otra variante: Celso Furtado — como sabemos discípulo de Prebisch y uno de los más imaginativos continuadores del pensamiento cepalino, fundador de la SUDENE y autor de nuestra primera planificación económico-social en los comienzos de los 60- hablaría de modernización sin desarrollo, es decir, de subdesarrollo. Y la modernización como enclave en un incipiente aparato productivo de los elevados patrones de consumo de las élites es el nicho de la Arquitectura Moderna Brasileña. Por ello la ambigüedad: prometía desarrollo, esto es, homogeneización social en un país dual, cuando en verdad sólo profundizaba una modernización restringida; y el carácter postizo del injerto. Falsedad también en su asociación patriótica con el desarrollismo; en términos de Celso Furtado, uno y otro, fachada. Los textos y las obras de los años 50, en especial Brasilia, serán la prueba más cabal de la naturaleza de nuestra modernización -incluida la arquitectura y no como factor menor. De cualquier modo, no debemos olvidar que, a pesar del carácter institucional que tuvo la moderna arquitectura brasileña desde sus orígenes, las promesas que acompañaban la revolución del 30, en su victoria contra las oligarquías locales, no hacían prever el desvío fascista posterior. Dichas promesas moviliza- 
ron buena parte de la intelectualidad progresista que, en un segundo momento, continuará vinculada contradictoriamente a un Estado ya autoritario viendo en el take off industrializador y en sus preocupaciones de autopropaganda posibilidades paradojales de, por ejemplo, "realizar, los ideales democráticos y sociales implícitos en los principios racionales y funcionalistas del Movimiento Moderno" o continuar creyendo en las "virtualidades democráticas de la producción en masa" y otros espejismos. Con estas palabras intentará justificar el proceso el crítico Mário Pedrosa, insospechable de hacer concesiones a cualquier tipo de régimen antidemocrático al punto que salió al exilio el mismo año en que Le Corbusier llegó al Brasil. Así, aunque era consciente de las contradicciones generadas por la oficialización de una arquitectura concebida como "el gusto por lo suntuoso y la riqueza para impresionar a los responsables de la dictadura, simbolizada, quizás, por el brío a veces excesivo y las formas gratuitas que se hicieron moda", el mismo crítico se embarcó en la utopía de Lucio Costa, fortalecida, en la década del 50, por un nuevo asomo local de desarrollismo: la Brasilia de J.K. Por otra parte, atemperaba la adhesión entusiasmada con las dudas de quien conoce su país: "la Brasilia de Lucio Costa es una bella utopía, pero ¿tendrá algo que ver con la Brasilia que Juscelino Kubitschek quiere edificar?” O: “¿cómo confiar una tarea tan trascendente a un gobierno tan turbio como el actual?". Inquietudes en el fondo proporcionales a la magnitud de las esperanzas alentadas por la industrialización de aquellos años dorados.

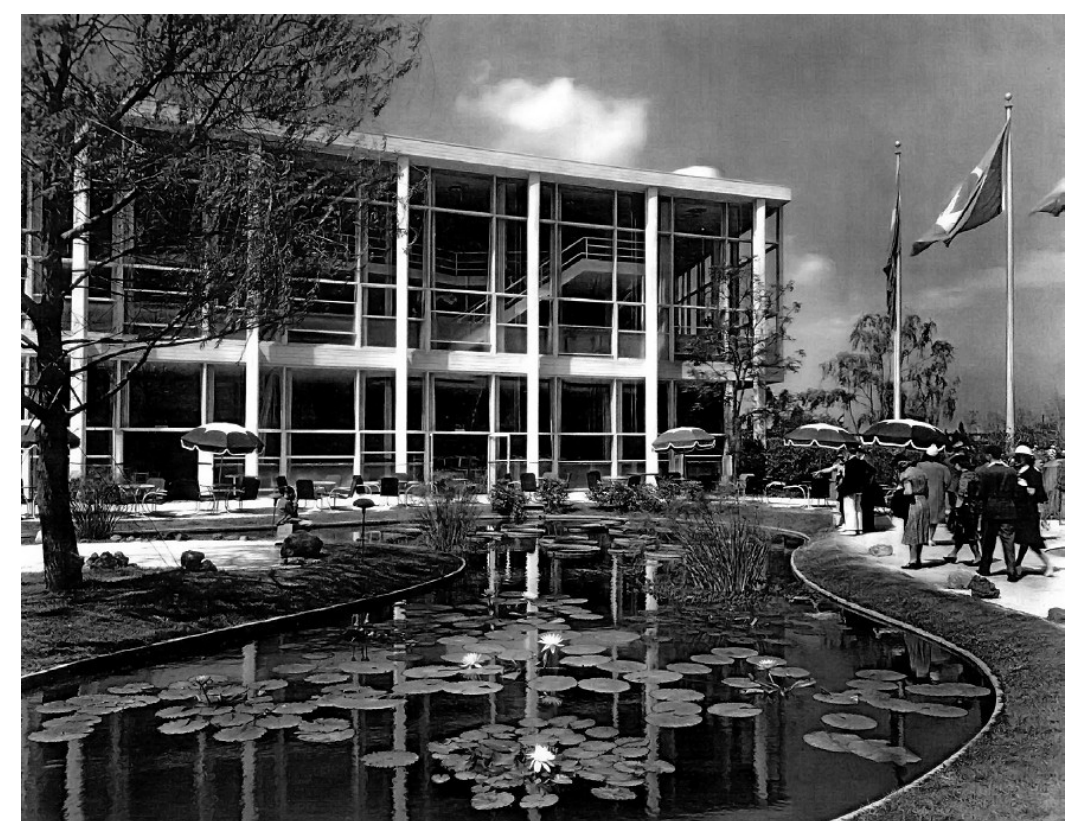

Lucio Costa e Oscar Niemeyer, Pabellón de Brasil, Feria Universal en Nueva York, 1938

Pero antes de llegar a ese momento, deben pasar más de veinte años narrados por Lucio Costa como de un "acierto" histórico. No lo negaré, aunque, con todo respeto por la proeza de hecho monumental, alegaré razones que no son seguramente las del autor. Una vez más me anticipo; usando una fórmula famosa en los tiempos de la inauguración de Brasilia para caracterizar esa reversión de la conciencia del atraso después del 30: es imposible dejar de reconocer en la marcha triunfal de la moderna arquitectura nacional "la marca cruel del subdesarrollo". Sin embargo, creo que resulta pertinente continuar hablando de "acierto"; por otra parte, éste es precisamente el caso en el que pesaron de modo decisivo las previsiones del Maestro. Vuelvo al itinerario de Lucio Costa, aunque en 
rigor no me haya apartado de él, pues seguimos tratando de una trayectoria no lineal de vida y obra que se cruzaba, incluso sin saberlo, con los protagonistas del Movimiento Modernista brasileño de la década del 20 y con un esquema ajeno -la "liberación localista de lo reprimido"- que les permitió polemizar, aunque fuera por broma, con el mundo que la burguesía europea creara, y ahora se presentaba como último recurso de una causa que aún no se sabia perdida. Así permaneció durante un período largo, como música de fondo apenas audible, ya que, con aguda conciencia del drama material del subdesarrollo, ese período no admitía apelación alguna a la extinta ideología del "carácter nacional". (Hasta que otro colapso la resucitase; pero éste es asunto para otra inquisición).

Retomo los hechos: después del Salón del 31, por invitación de Lucio Costa que en ese tiempo se tornó su colaborador, Warchawchick se estableció por un tiempo en Río. Mientras proyectaba una serie de casas "sin dueño", L.C. construyó otras, pero fundamentalmente, atravesó un período que llamó de chômage y gracias al cual tuvo la oportunidad de estudiar a los Modernos, en especial, a Le Corbusier que le pareció el más sugerente de todos, por haber sabido combinar como nadie las tres dimensiones esenciales de la buena arquitectura: la técnica, la social y la artística. Bien asimiladas, estas lecciones aparecen tanto en textos y memorias como en proyectos. Quizás el más importante efecto de este aprendizaje: Lucio Costa, que no había prestado atención a la llegada al Brasil del arquitecto suizo en 1929, luego de siete años propondrá a Gustavo Capanema (ministro de Educación del gobierno de Vargas) traerlo para juzgar el proyecto de la Universidad y del edificio del Ministerio de Educación y Salud Pública (MESP), ambos prioridades del ministro, que debían simbolizar una reforma de la educación a la altura de los nuevos tiempos (estábamos en plena era Vargas y en las vísperas del Estado Nuevo); el campus sería obra de Piacentini -al que Capanema se empecinaba en ver como un moderno y no como un fascista-y el proyecto para el edificio del MESP se decidió mediante un concurso que ganó Archimedes Memória con un predio de estilo marayoara. Se hizo sentir entonces la influencia decisiva de Lucio Costa, que alteró completamente los rumbos que tomaban las iniciativas: convenció al ministro y al presidente para que trajeran al "mayor arquitecto de la actualidad". Fue así como en el 36 llegaba al Brasil Le Corbusier quien rehizo el anteproyecto de la ciudad Universitaria y el primer estudio del Ministerio, además de dar conferencias en Río y San Pablo sobre la Nueva Arquitectura.

Por ese tiempo, se había constituido en Río un grupo de jóvenes arquitectos bajo la orientación de Lucio Costa que -según él decía- convirtieron a los textos de Le Corbusier en el Libro Sagrado de la Arquitectura; con ellos continuó los dos proyectos. El núcleo estaba tan cohesionado por la impregnación de las lecciones del Maestro que, cuando se presentó la oportunidad de poner en práctica la teoría, la respuesta fue instantánea y adoptó la forma de "espontánea contribución nativa" -como dirá más tarde Lucio Costa, agregando: estaban tan imbuidos de la necesidad de conciliar arte y técnica y (de acuerdo con el recetario corbusiano) de dar a la generalidad de los hombres la vida sana, que "la Edad de la Máquina técnicamente faculta", que, sin querer, se tornaron modernos. Así, en el 37, comenzaba el Ministerio de Educación -inaugurado en el 45- bajo el signo de la modernidad técnica y con la participación de Oscar Niemeyer, Carlos Leão, Affonso Reidy, Jorge Moreira y Ernani Vasconcellos. 


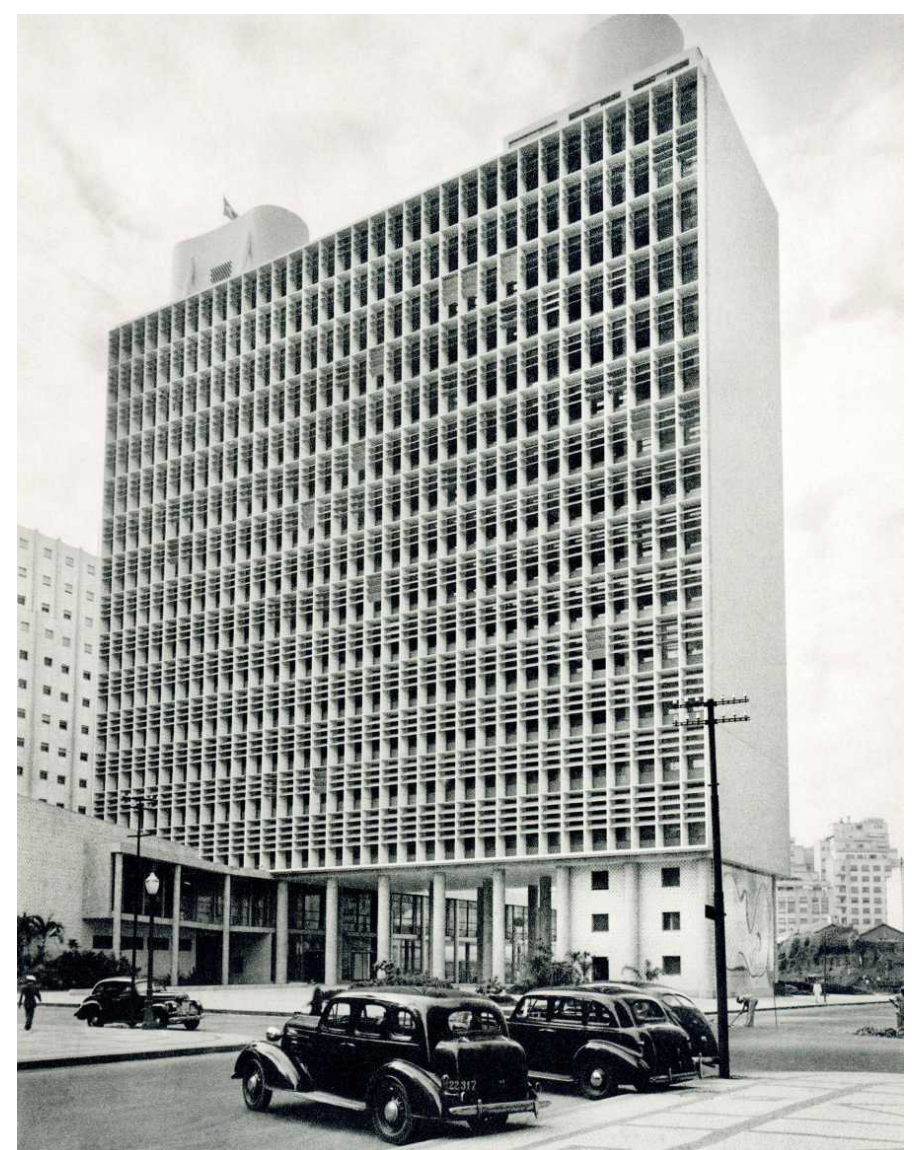

Affonso Eduardo Reidy, Carlos Leão, Ernani Vasconcelos, Jorge Machado Moreira, Lucio Costa y Oscar Niemeyer,

Ministério de Educación y Salud Pública,

Rio de Janeiro, 1936

El proyecto, aunque basado en el boceto original del mismo Le Corbusier y obediente de las cinco máximas del Maestro, sufriría "adaptaciones" que señalaban los nuevos rumbos de nuestra arquitectura: el cambio de escala de los pilotes, la verticalidad del edificio, los volúmenes entrelazados, la implantación en el terreno, los agregados de los brise-soleil en la fachada y los azu- lejos con dibujos de Portinari, soluciones éstas que no sólo "abrasileñaban" el proyecto de Le Corbusier sino que, cumpliendo el papel inherente a una iniciativa patrocinada por el Estado, monumentalizaban el edificio, volviéndolo matriz y símbolo de nuestra arquitectura y nuestra modernidad -que tendrá su epílogo apoteótico, como es sabido, en Brasilia. Como escribió el mismo Lucio Costa sobre el MESP: "Marco definitivo de la nueva arquitectura brasileña que, apenas construido, habría de revelar también un patrón internacional y donde la doctrina y las soluciones preconizadas por Le Corbusier tomaron cuerpo por primera vez en su aspecto monumental". Como se ve, un monumento brasileño a la Arquitectura Moderna mundial.

Por lo tanto, "no sólo cambio de escenario" sino también "estreno de pieza nueva en temporada que se inaugura". La feliz imagen es usada por Lucio Costa -en su famoso texto del 51 que citamos al comienzo- para caracterizar las transformaciones resultantes de mudanzas técnicas capaces de abrir otro ciclo económico y social. Por eso mismo, es una "revolución" aunque ocurrida por "milagro" (el sentido del término comienza a aclararse); y explica: "milagro double-face si pensamos en la proverbial ineficiencia de nuestros operarios o en el atraso de nuestra industria en comparación con el salto ocurrido en los usos y costumbres de la población, en la capacidad de los talleres y la competencia de los profesionales (...)pasando a encabezar súbitamente y por consenso unánime de la crítica extranjera idónea, el período de renovación que ha venido atravesando la arquitectura contemporánea". 


\section{Historia de una Formación}

Lucio Costa reconoce -siempre según el balance del 51que, aún de modo esporádico, la Arquitectura Moderna comenzaba a afincarse entre nosotros: Warchawchik en San Pablo; en Río, el albergue de la Buena Voluntad de Reidy y Pinheiro, las casas que el mismo Costa construyó con Warchawchik, los departamentos de Luis Nunes (que se estableció después en Recife), las primeras casas de Marcelo Roberto, las obras de los ingenieros Fragelli, Paulo Camargo, Paulo Antunes, volviendo a San Pablo, Vital Brasil; y aún más, los primeros proyectos de Carlos Leão, Jorge Moreira, José Reis, Firmino Saldanha, seguido de Oscar Niemeyer, Alcides da Rocha Miranda, Milton Roberto, Aldary Toledo, Ernani Vasconcellos, Fernando de Brito, Hélio Uchoa, Hermínio Silva y otros. El primer edificio proyectado sobre pilotes (del 33 o 34, donde vivió Lucio Costa) de autoría de Paulo Camargo, el primer brise-soleil de láminas verticales basculantes de Baldassini (uno de los arquitectos presentes en el Salón del 31) y otras iniciativas más. Pero el marco definitivo habrá de ser el predio del Ministerio. Entre tanto, se construían otros edificios: la ABI de los hermanos Roberto, la Obra do Berço, la Estación de Hidroaviones. Sin embargo, nada hay que sintetice de forma tan perfecta lo que se reconocería de ahí en más como modelo de Arquitectura Moderna y Brasileña como el MESP, símbolo incuestionable de algo realmente NUEVO.

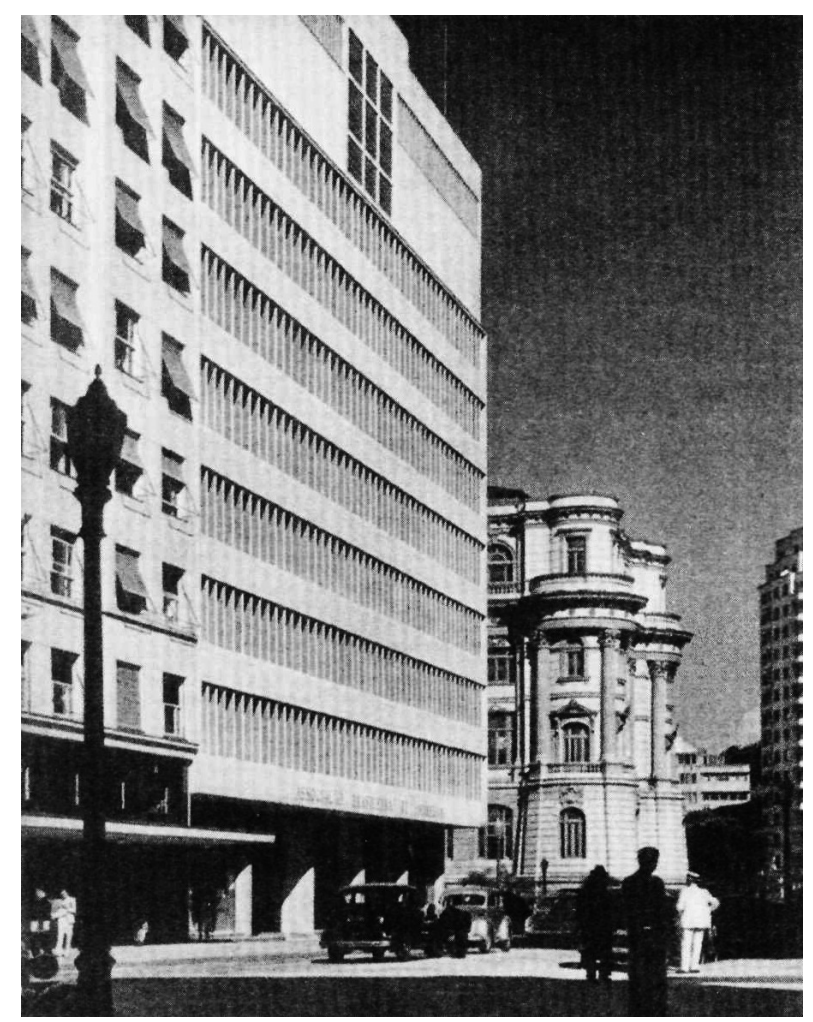

Hermanos Roberto, Associación brasileña de Imprensa, Rio de Janeiro, 1936-39

Un proyecto de tal magnitud - una arquitectura moderna paradigmática en un país todavía inacabado- no podía restringirse a hechos aislados y sin futuro, en general, puramente imitativos. ¿Qué podía esperarse, por ejemplo, de una intervención del tipo "primera casa modernista" sino otras iniciativas pioneras individuales? (Así lo explica Lucio Costa en su carta-testimonio a Geraldo Ferraz, de 1948, después de hacer las aclaraciones correspondientes respecto del aprecio que siempre le había merecido la obra de su gran amigo y ex-socio, Gregory Warchawchik). Lo mismo se puede decir de todos los 
otros "ensayos" a los que se refiere. Ser moderno, por el contrario, requería la voluntad consciente de suplantar ese momento indeciso de manifestaciones vanguardistas solitarias. La cristalización se produjo, como vimos, con la Revolución del 30. En poco más de diez años se formó la Arquitectura Moderna Brasileña. Luego, aproximadamente en la segunda mitad de los años 40, su principal protagonista e ideólogo comenzó a contar, con un sinnúmero de variantes, lo que podría llamarse la historia de los brasileños en su deseo de tener una arquitectura coherentemente moderna. (Es la expresión de Antonio Candido cuando se refiere a las "motivaciones" en el origen de la formación de nuestra literatura; de hecho, una variante de la fórmula adoptada por Machado de Assis en 1873, al explicar a los americanos cómo la literatura brasileña empezaba a constituirse gracias al "instinto de nacionalidad" que se afirmaba: "el deseo general de crear una literatura más independiente"). Sin embargo, como contrapartida a este aparente avance de nuestra arquitectura -si tenemos en mente algo como la modernización del Brasil de los Modernistas-, la supresión actual del complejo de inferioridad, sin la memoria activa de la etapa anterior, perdía el filo y volvía al programa simplemente afirmativo de actualización necesaria, comandada, por otra parte, por un Estado fuerte y emprendedor. De ahí en más, el mano a mano simbólico no ponía nada en jaque; el futuro edificio-sede del Ministerio de Educación sólo probaría que el país podía tener una arquitectura de primera línea tan buena, o hasta mejor, que la de los países centrales que, por otra parte, debían todavía una muestra cabal, como sabía bien et pour cause el propio Le Corbusier,

La historia ejemplar que Lucio Costa contó entonces, podría ser resumida, en la medida de lo posible, en sus mismas palabras. La tarea de implantar en un medio alternativamente desinteresado $u$ hostil, la nueva manera de concebir, proyectar y construir; el proceso de renovación esbozado de modo individual en algunos lugares comenzó por fin a afincarse y organizarse cuando, apartando a intermediarios y francotiradores, se estableció un vínculo directo con las fuentes originales del movimiento mundial; es decir, cuando fructificaron las simientes auténticas plantadas aquí por Le Corbusier en 1936 (como vimos, por iniciativa de Lucio Costa, que nunca dejó de atribuirle los créditos - desde el "boceto" original del Ministerio de Educación a las ideas básicas que inspiraron Brasilia). Se dio, entonces, aquel "milagro" que desafió la curiosidad perpleja de arquitectos y críticos europeos y norteamericanos, doce años después de la primera casa modernista brasileña, un experimento notable pero sin mayores consecuencias. Sucedería lo contrario con el Ministerio (y sus descendientes inmediatos) puesto que definió el sentido general de los acontecimientos y certificó el alto grado de conciencia y capacidad alcanzados: en primer término, los predios proyectados y construidos durante el largo y accidentado transcurso de las obras de ese edificio inaugural; luego, el Pabellón de Nueva York; finalmente, el conjunto de Pampulha. (Lucio Costa podría haber incluido su conjunto del Parque Guinle, pero no lo hizo. Méritos aparte, si el modelo victorioso hubiera sido éste, el futuro de la arquitectura que fue identificada desde entonces como la Arquitectura Moderna Brasileña habría sido otro; pero el Maestro Lucio, como un metteur-en-scene consciente no dudó en definir cómo debía proseguir el espectáculo. Porque de eso se trata, para bien o para mal: de una arquitectura espectacular). Así, de las manifestaciones al sistema habían transcurrido menos de dos décadas; un aparato de 
hecho impresionante, sobre todo por la pericia técnica demostrada en tan poco tiempo de ensayo general. Algo así como un milagro... como dijimos. Y Lucio Costa da a entender, sutilmente, que todo podía ser, también, fruto de una feliz coincidencia; por ejemplo, la presencia de una personalidad que estuvo en los tres episodios, una personalidad capaz de captar las posibilidades latentes y darles una respuesta a su altura, y que sería decisiva para la arquitectura brasileña contemporánea, el joven Oscar Niemeyer. "Desde ese momento, el rumbo diferente se impuso y la nueva era estaba asegurada", concluye.

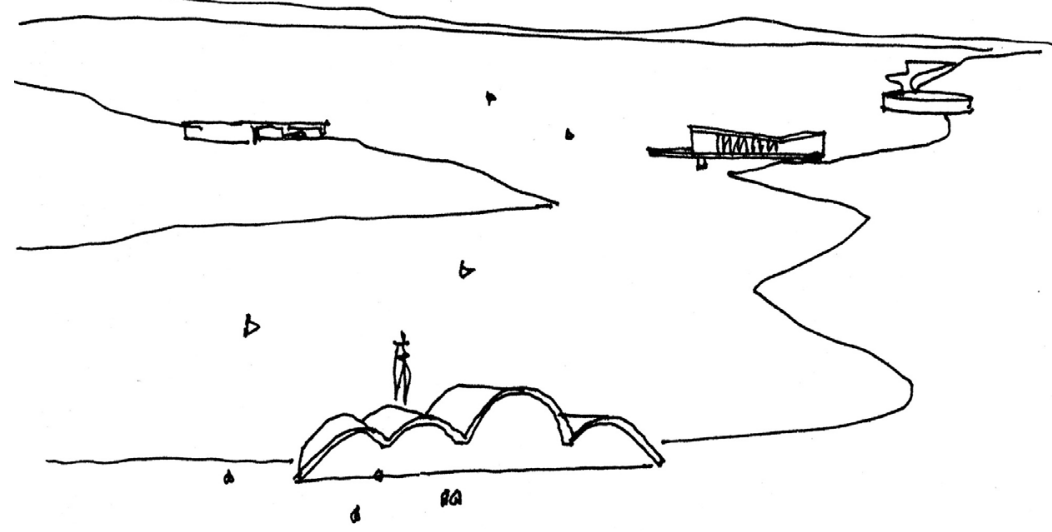

Oscar Niemeyer, Diseño del conjunto de la Pampulha, Belo Horizonte, 1943

Nuestro gran personaje dio entonces un segundo paso, el remate verosímil que certificaba la mayoría de edad alcanzada, la visión retrospectiva que ordenaba un pasado hasta ese momento incomodo. Volviendo definitivamente convincente la coherencia lógica del pa- saje, quiso el destino que el demiurgo del Movimiento Moderno en Brasil, ligado desde 1937 al SPHAN (Servicio de Patrimonio Histórico y Arquitectónico Nacional), hubiera se transformado en un perito en materia de arquitectura tradicional. Así, se hacía posible recontar la historia de la arquitectura brasileña a la luz del exitoso injerto de la Nueva Construcción haciéndolo surgir milagrosamente del suelo brasileño. Lucio Costa llevó a cabo la tarea con tal brillo que hasta hoy le debemos la definición del camino que debía recorrer la historiografía brasileña de la arquitectura. Como su punto de vista era ya literalmente moderno y al mismo tiempo se había desarrollado desde la óptica de una formación reciente y en lo esencial realizada, era natural que comenzara a hurgar nuestro pasado arquitectónico al constatar la falta de una línea evolutiva que había conseguido descubrir en el desenlace contemporáneo, anulándole su posible rasgo intempestivo. O mejor, la misteriosa interrupción de dicha línea, puesto que, incluso en la fase considerada de alienación tradicionalista, durante los años 20, Lucio Costa había percibido que desde hacía más de un siglo, de repente, alguna cosa que andaba bien había desaparecido, se había perdido lo que comenzaba a apreciar con gusto de experto: la arquitectura robusta de líneas calmas y tranquilas de los maestros anónimos de la construcción civil colonial. Más tarde extendería aquella línea evolutiva general hasta el Imperio o el comienzo de la República, línea general identificada por contraste con el desorden correspondiente al período subsiguiente del eclecticismo histórico de base académica. Porque estaba instalado en lo alto de la formación moderna consumada, los hechos relacionados con la arquitectura de Brasil en el medio siglo precedente sólo po- 
dían presentarse, incluso con mayor nitidez, como una sucesión disconexa de episodios disparatados; nada, en fin, que permitiera presentir la etapa preparatoria para lo que ocurriría. Estoy refiriéndome al esquema de la formación de la arquitectura en los mismos términos del ensayo del 51. De la arquitectura que se quería reducida al mínimo -la "muchacha despierta, de cara lavada y pierna fina", como imaginaba la Nueva Construcción de los años 30- a aquella llena de "encanto" y "gracia" cuyo mejor ejemplo era Pampulha; así opinó el Maestro Lucio cuando inquirido por Geraldo Ferraz en el 48 y lo repitió a Max Bill, en el 53. Por otra parte, ante el carácter de excepción que éste le otorgó a la "espléndida realización de Pedregulho" (la obra de Affonso Reidy), no vacilará en afirmar categóricamente y sin quitarle mérito: "la arquitectura brasileña en su aspecto actual -incluyendo el Pedregulho- no existiría. Fue allí (en Pampulha) donde se definieron sus características diferenciales" .Tal vez la clave del enigma esté ahí: la "buena causa" de la arquitectura nacional, aquella misma que - según dice - lo decidió a llevar al joven Niemeyer a Nueva York para colaborar en el proyecto del Pabellón que comenzó nuestra fama en el exterior (estábamos en 1938). Una causa tan buena no podía ser confiada a manos mejores, dotadas -y no por azar- para el juego abstracto con las formas.
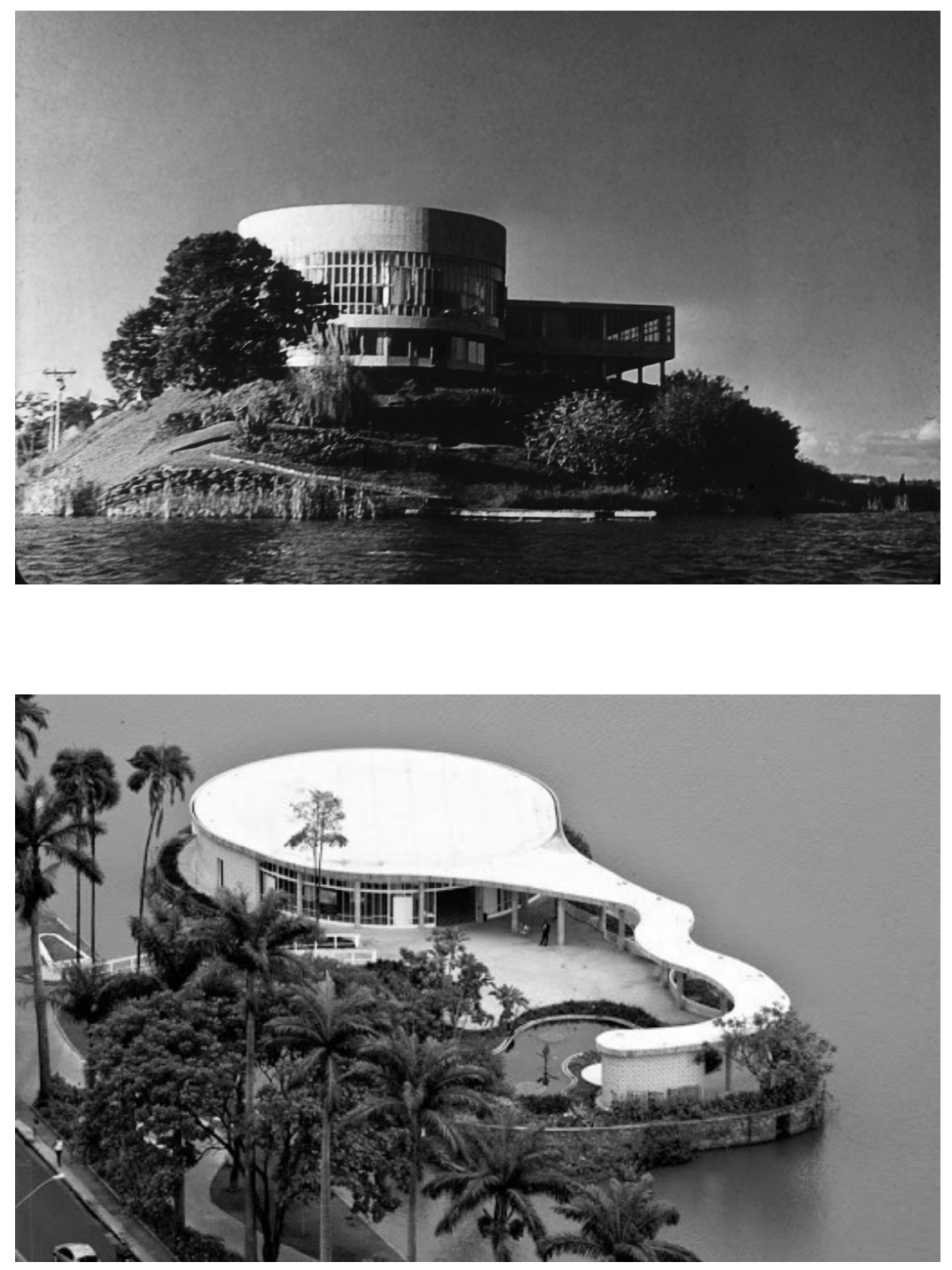

Oscar Niemeyer, Casino y Casa de Baile, Pampulha, 1943

Para entender el propósito de Lucio Costa de contar la historia de una arquitectura exitosa, es necesario recordar que volvía a un viejo problema de nuestra crítica, el de la oscilación entre lo local y lo mundial y las ideas generales en torno a un punto de equilibrio buscado en la inte- 
gración progresiva de la doble fidelidad que preocupa a todo ciudadano de un país aún en fase de transición. En la misma época (años 50) Antonio Candido escribía el libro que se tornaría referencia obligatoria-la Formación de la literatura brasileña, ya citado-; sin embargo, y aunque sea el primero en explicarla cabalmente, la idea de "formación" aparece de manera obsesiva como centro de varios libros fundadores de nuestra tradición crítica, incluso cuando no tome ese nombre, tal es el caso de Raíces del Brasil de Sérgio Buarque de Holanda. Otros ejemplos: Formación del Brasil contemporáneo, Formación Económica del Brasil, Formación Política del Brasil, Formación del Patronato político Brasileño, etc. En ella se concentra lo esencial del debate intelectual brasileño, que siempre giró en torno a la cuestión crucial -moderna por excelencia- del pasaje de la Colonia a la Nación. Se trata, entonces, de la formación nacional sobre el telón de fondo de la eternamente presente herencia colonial que debe ser superada. Al contar la historia de los brasileños en su deseo de tener una literatura, Antonio Candido reencontró, en el plano de la vida mental, aquel mismo impulso constructivo responsable por la articulación de lo que llamó sistema literario - un campo de referencias cruzadas acumulativas entre autores, obras y público; la constitución, en fin, de una continuidad literaria a través de la que pasaría, por el filtro de las formas, el sentimiento del país. En la comparación obligatoria que se establecía con la norma europea a la que se aspiraba, pasaría también el sentimiento del mundo, exaltado o rebajado por el localismo hasta el momento en que el equilibrio entre ambos sería alcanzado en la obra de Machado de Assis, cuando se completa la "formación" del sistema. Como la literatura había ocupado un lugar central en la organización de la experiencia nacional en el siglo XIX, en tanto factor de revelación del país, Antonio Candido dio con la clave interpretativa del sistema cultural brasileño. Creo que -respetando las peculiaridades de otros dominios-es posible reencontrar, con facilidad, esa misma matriz en la pintura, en el teatro, en el cine y en otros campos.

Quizás el esquema básico pueda resumirse en los siguientes términos: "formación" es propósito constructivo, deliberado de las élites dirigentes y cultivadas para dotar al país de líneas evolutivas que culminen en el funcionamiento coherente de un sistema cultural local, tomando por modelo y parámetro crítico la relativa organicidad de la vida cultural europea en lo que concierne a su capacidad de incidir (y formalizar) en el campo de fuerzas constituidas por la sociedad moderna. Por lo tanto, supone el ideal de serialización, concatenación, continuidad y tradición como contrapartida de la confusión de nuestra vida mental, en donde nada deriva de nada, donde lo acumulado puede ser rápidamente borrado por algo prestigioso aunque extrínseco al cuadro de contradicciones locales que, trabajosamente, buscaba reconstituirse. Es decir, supone un sistema de referencias recíprocas que se contraponen a las manifestaciones súbitas y aisladas. Y, porque el proceso de la formación se cumplía sin interrupciones, tarde o temprano, se concretaría una especie de causalidad interna o línea evolutiva cuya fuerza, proveniente de la capacidad de poner en "forma" el proceso local, terminaría por redundar (era el deseo de Antonio Candido al estudiar la formación de nuestra literatura) en superación de la dependencia (lo que de hecho pasó con Machado y posiblemente con nuestros grandes Maestros Modernos). Emanada de lo "alto", esta disposición tiene un color nacionalista que debe evaluarse en perspectiva y con sentido histórico de sus dimensiones. Nótese que, cuando sucedió el cambio 
formativo, Machado pudo, por primera vez, "retratar" mediante la forma-composicional un Brasil-proceso social y ya no un Brasil-identidad (carácter cultural) ${ }^{5}$. Vemos allí la importancia crucial de la referencia nacional que, cuando se eclipsa, hace que la vida intelectual se torne irrelevante. Pero referencia-proceso (parte del sistema mundial de contradicciones), lo contrario de referencia-identidad (mitológica, y actualmente mercadológica) - algo que no se puede olvidar cuando se vuelven a poner en circulación los clisés nacionales más decadentes para encuadrar nuestra arquitectura en un regionalismo más.

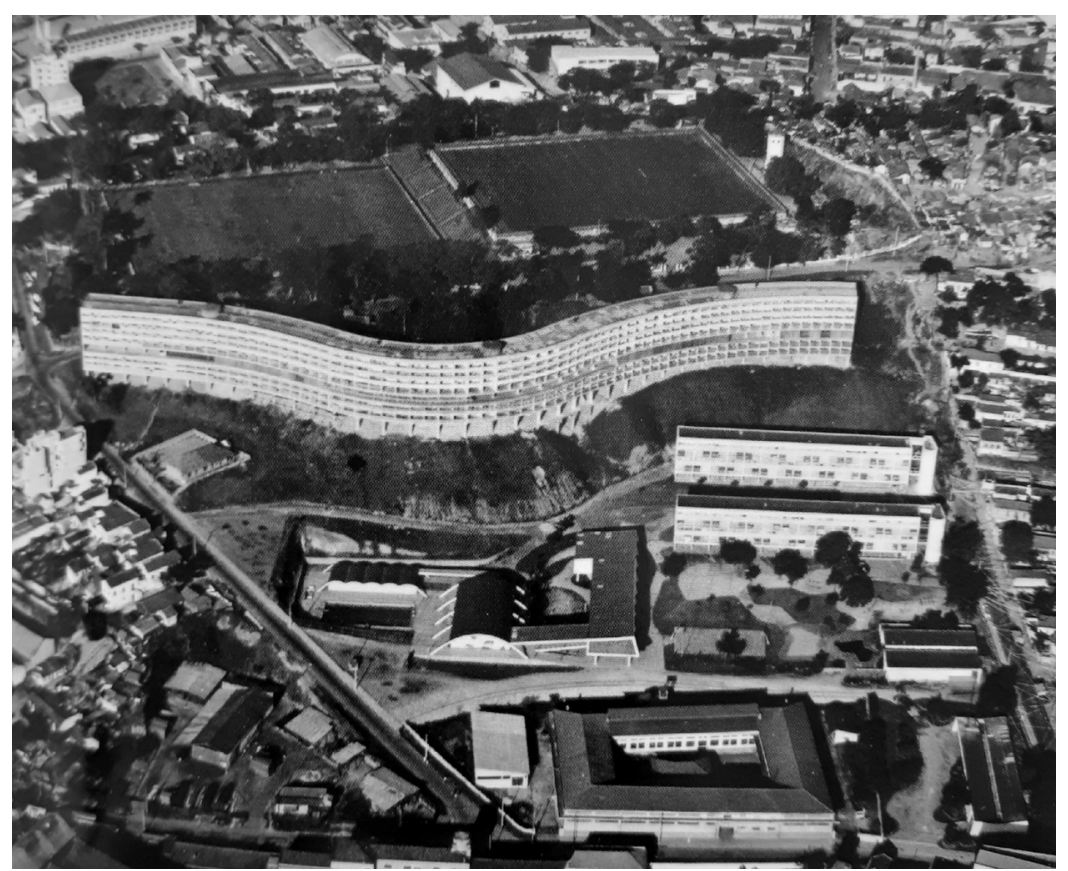

Affonso Eduardo Reidy, Conjunto residencial Pedregulho, Rio de Janeiro, 1950-52

5. Al hacer esta distinción, tanto quanto en muchas de mis consideraciones sobre nuestra modernización dependiente, me utilizo hartamente de los trabajos de Roberto Schwarz - principal discípulo e intérprete de Antonio Candido - sobre cultura brasileña y, en especial, sobre Machado de Assis.
Retornando a Lucio Costa y su "esquema" de formación, quizás haya llegado el momento de redefinir la arquitectura moderna nacional ya "formada". En primer lugar, recordemos que no habría formación sin el injerto plantado directamente por el propio Corbusier y, sobre todo, bajo el patrocinio de un Estado autoritario y proto-desarrollista: sin esa conjunción no existiría el genio de raza que realizara el deseo de los brasileños de tener una arquitectura a la altura de los nuevos tiempos; continuaríamos acumulando muestras gratuitas de casas modernistas que podrían estar en Higienópolis, Vila Mariana, o otros barrios de San Pablo, como en París o Viena. Se sobreentiende entonces, de modo esquemático: a) que, en los países dependientes, el influjo externo es preponderante (lo que no tendría sentido, por ejemplo, en Francia o en Inglaterra, países con un sistema cultural, por decir así, congénito); b) que la exigencia de actualización es un imperativo social y del sistema productivo; c) que no hay actualización sin un razonable desajuste ya que no hay forma sin presupuestos materiales correlativos y éstos no circulan como las ideas y las mercancías; d) que en el caso particular de la Arquitectura Moderna este desfasaje saltaba a la vista por conocidas razones del desfasaje histórico-material; e) el formalismo del transplante no se hizo esperar; el hecho fue visto por todo el mundo, por los brasileños antes que por los europeos, aunque aquéllos fingieron no ver (o hicieron de ello una virtud); f) razones del éxito mundial de público y crítica: aquella estilística suspendida en el aire, parecía brotar del centro mismo del Movimiento Moderno; no había nada más moderno que lo que estaba pasando en Brasil en materia de arquitectura; g) demostración del formalismo-abstracción intrínseco a la Ideología del Plan, explicando su migración exitosa hacia la periferia 
del capitalismo; h) sucedió, entonces, lo que nadie podía prever, un fenómeno notable de decantación; el Brasil como lugar de decantación de la Arquitectura Moderna: el desajuste local revela, como si fuera su verdad, el fondo falso del original, aunque se vea así desde la perspectiva del observador no implicado en ninguno de los dos términos que se refuerzan mutuamente y son, por lo tanto, cómplices ideológicos (caso único puesto que, en general, el injerto abortado compromete sólo la incompetencia congénita de la copia); i) sin embargo, hay en este modelo explicativo algo más, verdaderamente original. El desacierto exitoso - que podría funcionar como plataforma crítica de observación de la Arquitectura Moderna en el plano mundial, en nombre del análisis de la experiencia local malograda-, fue transfigurado en revelación plástica del pasado arquitectónico local, dando al país el título de "creador endógeno del Movimiento Moderno" que sólo tendrá existencia en tanto manifestación local. De allí a la actual fraseología y práctica culturalistas, no hay más que un paso.

Concluyendo provisoria y parcialmente: se reveló aquí la falsedad local de la matriz universal y, al mismo tiempo, la verdad mundial de lo falso local, es decir, una descalificación recíproca, un desmentido o crítica mutua que no estaba en el programa: de allí, el privilegio de un punto de vista crítico anclado en la experiencia brasileña cuyo alcance es mundial. Esos elementos "formativos" del sistema cultural brasileño están presentes en el esfuerzo de la teoría y del proyecto de Lucio Costa. Vemos pues, que, para su exacto entendimiento, no sólo es posible sino también necesario hablar de una formación de la arquitectura moderna en el Brasil, que es, de este modo, el horizonte real del "esquema" de L.C. Propósito deliberado de actualización y equilibrio del Brasil con respecto al resto del mundo civilizado. No será Nación (después de haber sido Colonia) sin auxilio de las técnicas constructivas más avanzadas. El "esquema" - incomprensible sin el decisivo cambio de eje que produce en nuestra vida mental la Revolución del 30- puede ser resumido así: nuevamente, la cultura moderna es instrumento del descubrimiento en principio no oficial de la llamada a partir de entonces "realidad brasileña".

Sucede que aquel argumento es, cuando mucho, un bello voto piadoso. Aunque fuertemente apoyado en la realidad, o mejor, por eso mismo, se trata de un cuento bien urdido -que, por otra parte, concuerda, como vimos, con una especie de lógica espontánea de formación, una suerte de esquema mental brasileño que guía los pasos de nuestros mejores espíritus-, una fantasía exacta que asumió, desde ese momento, dimensiones mitológicas. Así lo demuestra el éxito con que cada obra de la Arquitectura Moderna Brasileña, grandiosa o no, reforzaba la fábula de su propio origen milagroso. Las cosas no ocurrieron de esa manera. No negamos la formación de la arquitectura brasileña; por contrario, el problema comienza con la fortuna de su madurez precoz. Exito de público y de formación, la arquitectura brasileña moderna corre, desde la cuna, por una ruta inexistente (según la fórmula de Oswald de Andrade en el prefacio a Serafim Ponte Grande donde recapitula su carrera) y no hay remedio que la ponga en buen camino, simplemente porque no existe. Es más: su marcha consagratoria es la prueba fehaciente de esa inexistencia.

Me restrinjo al enunciado general, recordando de paso, para facilitar el argumento, una circunstancia conocida por todos. En lo que respecta a los hechos de la 
arquitectura brasileña, desde los primeros tiempos del milagro, la unanimidad internacional estuvo acotada por algunas restricciones que resultan, en general, de la completa ineptitud de la mayor parte de los extranjeros para apreciar nuestras singularidades. Así, donde se acostumbraba a ver levedad y gracia, en el modo brasileño de esquivar la magra e insípida dieta funcionalista, la miopía de la crítica internacional (Pevsner, Max Bill, Alvar Aalto, Banham, Nervi, etc) insistía en ver sólo indisciplina programática, excesos formales, irracionalidad en la adecuación de medios y fines. Como era de esperarse, ambas partes involucradas en el conflicto de interpretaciones reclamaban en su favor el desajuste flagrante entre la precaria o casi nula base material local y la exigida por la nueva racionalidad constructiva que se estaba trasplantando para bien del equipamiento moderno del país. Los dos lados reconocían un desajuste que les parecía obvio: los extranjeros, para denunciar la infidelidad a los principios, a la buena doctrina desfigurada; los nacionales, para reivindicar la ventaja del atraso que les había permitido liberar la invención plástica de las constricciones utilitarias de las viejas sociedades sin imaginación. En rigor, el contrapunto no pasa de un coro de engaños. Es lo que sucede con un trasplante exitoso: celebrarlo (como los nacionales) o descartarlo (como los ideólogos extranjeros) termina volviéndose una trampa mortal, pues lo que estaba ocurriendo aquí era ni más ni menos que la contraprueba espectacular de la quiebra mundial de la ideología arquitectónica, transfigurada en una ideología de segundo grado: la consagración de las virtudes nacionales.

Sin duda, la arquitectura moderna en el Brasil "resultó acertada" (como repitió innumerables veces Lucio
Costa, especialmente al defender a Brasilia) pero el problema está justamente allí: finalmente, en un país en que "para decirlo con propiedad, está todo por hacer”, ¿cómo implantar una arquitectura directamente vinculada con el progreso técnico? El desencuentro entre doctrina y presupuesto social es, de hecho, la regla en estos casos de injerto. Ni Lucio Costa, ni lo que pasó con nuestra arquitectura configuran la excepción a esa regla. Pero en este caso particular, y a pesar de la distancia real entre el centro avanzado y la periferia retardataria, se dio una notable inversión de los papeles, convirtiendo el desajuste en un gran acierto porque la distorsión de la copia fue lo que reveló la verdad profunda del original. El sesgo estético enaltecido como marca nacional sacó a la luz (tropical) del día el formalismo integral -la abstracción misma del espacio ordenado por el Capital. Sorpresas desagradables que deben atribuirse al desarrollo desigual y combinado del capitalismo. Siendo funcional y bonita para ver en la guarda colonial del sistema, donde en teoría nunca podría haber triunfado, la Nueva Construcción brasileña y su enorme carga simbólica —-mucho más institucional y monumental que propiamente social- se encargó, irónicamente, al imponerse en la periferia, de poner al desnudo las verdaderas razones de la Nueva Arquitectura. Además, si no teníamos una base material, productiva y social, acorde con los moldes requeridos por esta arquitectura, desarrollamos rápidamente una tecnología que parecía tener por única finalidad posibilitar tales arrobos formales: la tecnología de lo concreto, también como por "milagro", resultaba la más avanzada del mundo. Un caso típico en que los medios toman el lugar de los fines; más aún, una confirmación de que en la sociedad actual, la técnica reducida a fin en sí mismo transforma lo útil en su 
contrario. Dicha arquitectura, al intentar realizar los ideales estéticos de una obra autónoma, pura construcción, facilitada por los recursos tecnológicos disponibles (en el caso de la técnica del concreto armado), no contaminada por ninguna consideración de orden práctico y utilitario, no hizo más que reproducir, en la "pureza" de sus procedimientos, la lógica de la propia producción tecnológica heterónoma; y la "finalidad sin fin", involuntariamente parodiada, pasó a expresar la falsedad del proceso social en su conjunto, al que, en principio, debía oponerse; el sesgo estético que se quiso preservar en la arquitectura brasileña, despegado de lo social, y aparentemente - como toda obra de arte que se precie - sin función, acabó convirtiéndose en fetiche.

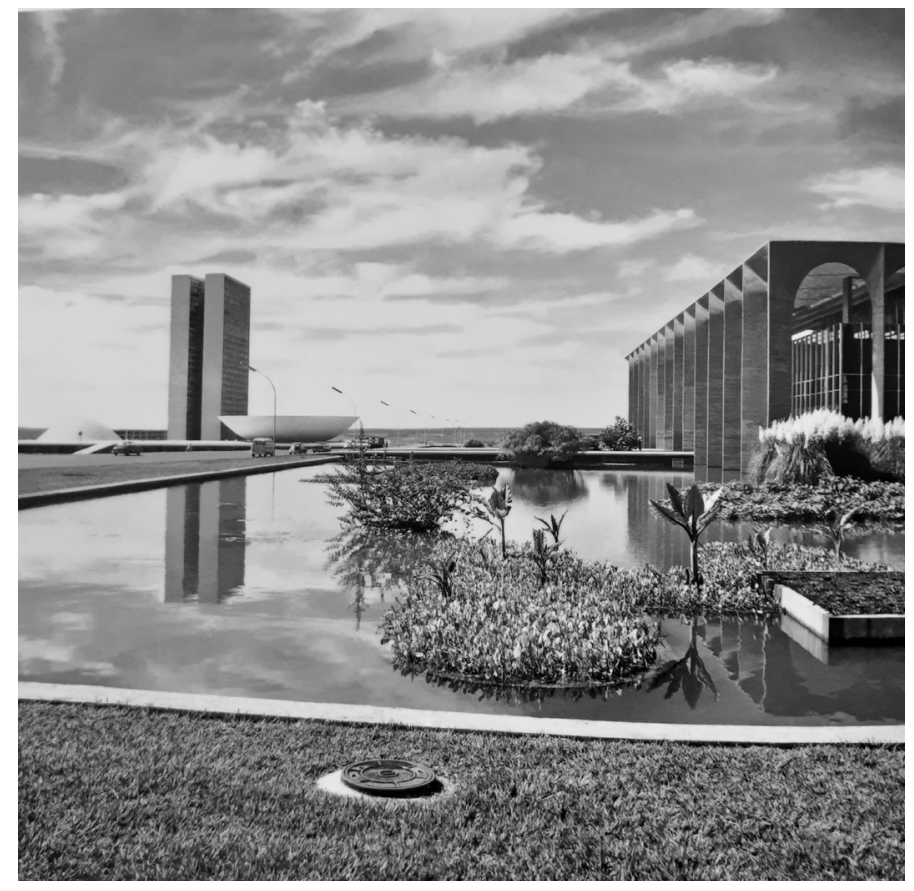

Marcel Gautherot (fotógrafo), Palácio de los Arcos y Cuadrado de los Tres Poderes, Brasilia
Por otra parte, no es nada improbable que en un determinado momento -tal vez hacia fines de los años 30 o un poco más tarde - haya comenzado a germinar el presentimiento funesto de que el triunfo internacional de la arquitectura brasileña se debía a la coherencia con que el Movimiento Moderno había sido obligado a confesar en la periferia lo que había escamoteado en el centro (por lo menos en los tiempos heroicos de las demostraciones aisladas), esto es -por poco que se entendiera la lógica productiva de la gran industria- que todo podía quedar en un simple juego abstracto de formas. ¿Qué hacer? ¿Retroceder? Finalmente, también en la arquitectura la tendencia histórica del material parecía señalar el camino tomado por los modernos. Justamente era ella, o el desarrollo de las técnicas productivas, que otorgaba al arquitecto la libertad para todo tipo de inventiva y de virtuosismo, campo en que nos mostrábamos eximios. Por lo tanto, era necesario continuar, aunque no de modo rutinario, por el camino previsible de toda modernización ya que teníamos el deber de velar por un éxito mundial en el que el país había comprometido su futuro. A pesar de un aparente contrasentido, la verdad es que la Nueva Construcción nos era funcional en todos los aspectos porque sirvió a los propósitos de modernización del Brasil (pasó a integrar la ideología del país "condenado a lo moderno" como gustaba decir Mario Pedrosa) y reveló la afinidad estructural de su programa técnico con la racionalidad del cálculo económico empresarial o del Estado, aún cuando su horizonte utópico parecía decir lo contrario. Podemos referirnos también a los componentes autoritarios que eran inherentes a su política de tabla rasa y de imposición del "punto de vista de la totalidad", en un país que mal había conocido algunos espasmos democráticos. Sin em- 
bargo, era justamente en esta sorprendente funcionalidad donde se manifestaba la paradoja a la que aludí: todo ocurría como si el Movimiento Moderno hubiera encontrado su verdadero lugar en la periferia del Capital y no en el centro Metropolitano para cuya reordenación espacial y habitacional había sido concebido. Con seguridad, el éxito resultó de la combinación de innumerables factores que, en general, no iban juntos, como por ejemplo, el ánimo cooperador de una izquierda que apostaba a los efectos positivos de la modernización capitalista en curso, impulsada por un Estado fuerte y desarrollista.

\section{Un remate}

Brasilia sería su expresión máxima y, como bien sostuvo Frampton, su límite, "su punto de crisis", sea por lo que su sectorización, que obedecía a jerarquías de clase y de poder, significaba, como explicitación y refuerzo de la segregación social existente en el país; sea por lo que su propia representación producía de "formalista y represivo". Podemos decir que ambas iban juntas y que cumplían rigurosamente la utopía corbusiana. Acumulábamos, por consiguiente, elementos para evaluar con recursos propios la quiebra mundial de la ideología del Plan, con todo lo que tiene de principio activo y al mismo tiempo ilusorio.

Sin embargo, y aunque es un capítulo esencial de esta historia, este paso conclusivo no había sido siquiera pensado cuando Lucio montó su "esquema". Conclusivo en todo sentido. De hecho, el cierre -triunfal, en esta ocasión- de un trayecto, personal y colectivo, que comenzara por un "milagro" (el Ministerio) y culmina- ra en un "espejismo" (Brasilia). Brasilia habría de ser el CQD de la fórmula exitosa de nuestra arquitectura: otra vez éramos pioneros en la aplicación íntegra del recetario moderno (CIAMs/Corbu) para la construcción de una ciudad a partir de cero. Del edificio a la ciudad. Todavía bajo el patrocinio del Estado transformado ahora en Estado para el Desarrollo; nuestra Arquitectura Moderna era el testimonio más visible de ese estado aunque, en alguna medida y por razones intrínsecas, ya se había mostrado necesariamente "desarrollista" avant la lettre (tomamos aquí al pie de la letra la definición de Celso Furtado: desarrollo como "aculturación" en que entran progreso técnico y reversión de la heterogeneidad social, aunque, una vez realizada, muestre lo contrario)

Si en los años 30, con el patrocinio del Estado, ya se podía hablar del deseo de los brasileños de tener una arquitectura moderna, sólo en los 50, esa arquitectura se torna emblemática de un Brasil moderno. Surge nuevamente como telón de fondo el debate nacional: el pasaje de Colonia a Nación, simbolizado en la plenitud retórica máxima de la fundación de una capital. En otro plano, se trata de una "clave de bóveda" (en la expresión de L.C. al defender su ciudad en 1967): momento decisivo en el camino ascendente de un pueblo subdesarrollado pero que reinventa su capital "bajo el signo del arte": una coronación cultural y un signo definitivo de madurez intelectual. 


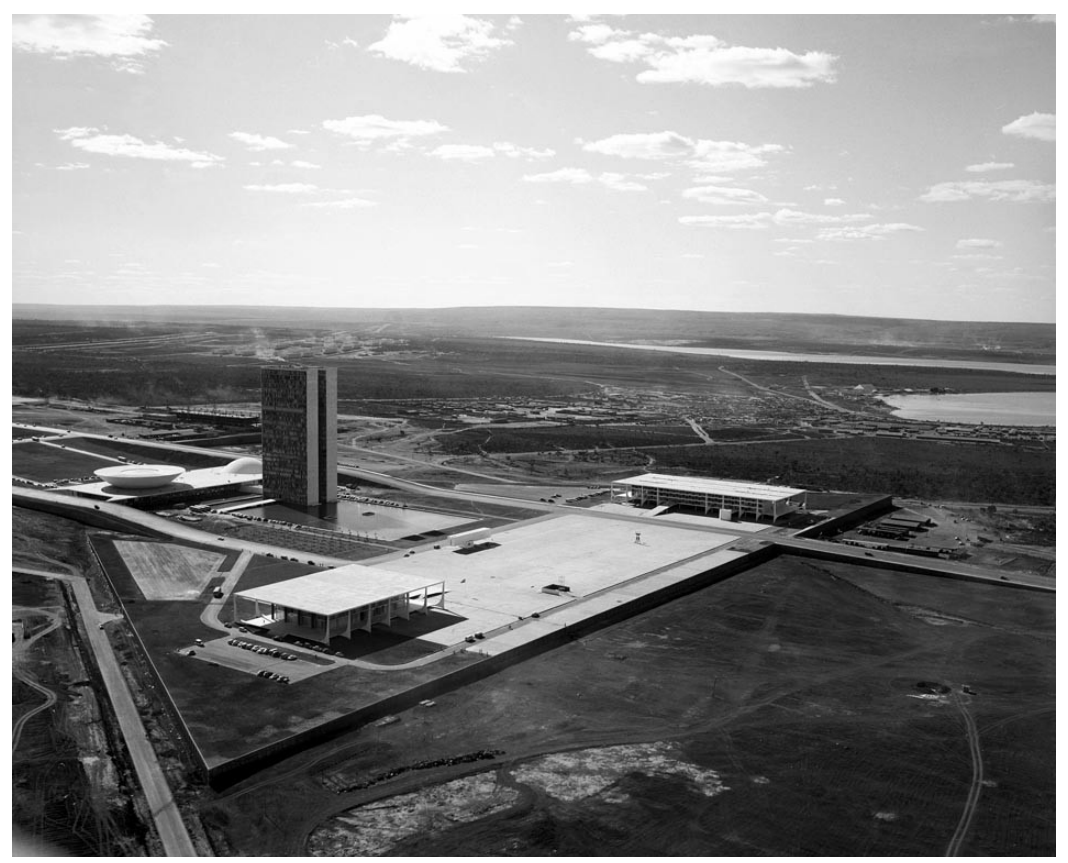

Lucio Costa e Oscar Niemeyer,

Cuadrado de los Tres Poderes y Eje Monumental,

Brasilia, 1960

Otro ejemplo de confluencia, una muestra del imaginario desarrollista de la época: tanto Lucio Costa como Antonio Candido dan el mismo ejemplo para el paradigma desarrollista de sustitución de importaciones o de pasaje de una economía primaria-exportadora a una economía industrial. L.C., hablando a los críticos: "ya no exportamos sólo café, azúcar, cacao; damos también un poco de comer a la cultura universal" ; A.C., en 1962, en el prefacio de la $2^{\circ}$ edición de Formación: "decir que los grandes temas son privilegio de las viejas literaturas es como decir que debemos exportar café, cacao o goma, dejando la industria para quien la originó históricamente". La misma imagen se encuentra en otros críticos de esa generación: cuando Décio de Almeida Prado opone el gran teatro de tesis a la pequeña comedia de costumbres que nos tocaría por vocación periférica o subalterna, o cuando Paulo Emilio Sales Gomes defiende nuestro deseo de tener un cine que no se restringiese a las viejas chanchadas o, aún peor, a la copia de la fotogenia hollywoodense.

Se trata, en rigor, de una "formación" doble: la del sistema cultural brasileño en sus varias ramificaciones (de la literatura a la arquitectura) y la de un sistema económico en tanto base material capaz de articular una sociedad nacional mínimamente homogénea. Ambas van juntas, sobre todo cuando el tema es Brasilia: una proyección mental impensable sin los requisitos materiales necesarios. La connotación desarrollista está ya presente en el nombre de Alvorada del palacio presidencial. Lo mismo sucede en el trazado del Plano Piloto, actualización de la cruz cabralina que anuncia un verdadero acto de refundación del país en la forma de un avión que aterriza en el planalto central. Paralelamente, ¿cómo no entrever en la imagen de la aeronave que sobrevuela el suelo rústico de la ex-colonia (hasta hoy país subdesarrollado) una más de nuestras modernizaciones concebidas desde lo alto, como suspendidas en el aire y que se desmoronan ante la menor sacudida del país antiguo pero real?

La verdad es que se trataba de desarrollo en lo concerniente a una concepción urbanística y una expresión arquitectónica singulares. Ambas se necesitaban para tal fin y tenían la ventaja de estar mentalmente disponibles, incluso en la forma de un acervo edificado. En rigor, el libro de L.C. es antes de todo el "registro de una vivencia"... del desarrollo, tanto más urgente (in extremis) cuanto más real se tornaba la amenaza de borrarlo de la vida colectiva. Lejos del lugar común o el clisé, Lucio Cos- 
ta tenía conciencia de eso. Observaciones tomadas de sus escritos de entonces demuestran que hablaba con pleno conocimiento de causa; todas ellas van a contrapelo de la sabiduría económica convencional: las referencias a la industrialización, la inflación, la infraestructura, las reformas de base-contrariando la falacia de la austeridad y de la estabilización monetarista- y sobre todo, la presencia del motivo "radical" que aflora en la "conciencia catastrófica o dramática del subdesarrollo", o sea, la ruptura con el mito conservador modernizante de la convergencia natural entre centro y periferia o del "estancamiento y pobreza sin esperanza". Oscilación entre pour y contre que es una constante de nuestra Arquitectura Moderna, incluso en su fase heroica de implantación y consolidación; aunque pretendiera afirmar nuestra modernidad brasileña y a pesar de la dimensión afirmativa pro-sistémica (equilibrar implicaba acatar esa modernidad acríticamente, como patrón civilizatorio), esa oscilación va siendo desentrañada paulatinamente en el mismo Movimiento Moderno a lo largo de su aculturación. De ahí que digamos que, en cierto sentido, esa arquitectura fue siempre "desarrollista" avant la lettre, reproduciendo la situación dramática de la modernización sin desarrollo de la que habla Celso Furtado.

Hoy, en esta nueva etapa en que la aspiración al desarrollo cedió a la visión apologética de la crisis, parece no haber quedado nada, más allá de un pasado glorioso, a pesar de que poseemos el mayor acervo a cielo abierto de la Arquitectura Moderna. La desintegración general que deriva de esa novísima situación de dependencia del capitalismo mundializado (la antigua reservaba una cierta área de maniobra para el Estado en asociación subordinada con los centros hegemónicos) no podría dejar de afectar de raíz nuestro ya debilitado pensamiento arquitectónico, herido de muerte después de Brasilia, en especial después del golpe militar de 1964. Bien o mal, nuestra festejada tradición moderna en arquitectura alimentó siempre la fantasía de estar a la vanguardia de la integración de las clases sociales más desfavorecidas -para decirlo con un eufemismo-, a la vanguardia del proceso de construcción nacional, de una sociedad industrial homogénea y coherentemente moderna. Con la preciosa colaboración de las coaliciones conservadoras locales, la mundialización del capital abortó esa construcción. Al mismo tiempo, dejó a la arquitectura brasileña sin asunto: ¿no había basado ésta su causa en el principio de la construcción abarcadora en grado máximo? Así, la utopía, que el capital había dibujado en el horizonte, fue reducida a polvo por el mismo capital, al cambiar de forma.

(Traducción: Adriana Rodríguez Pérsico)

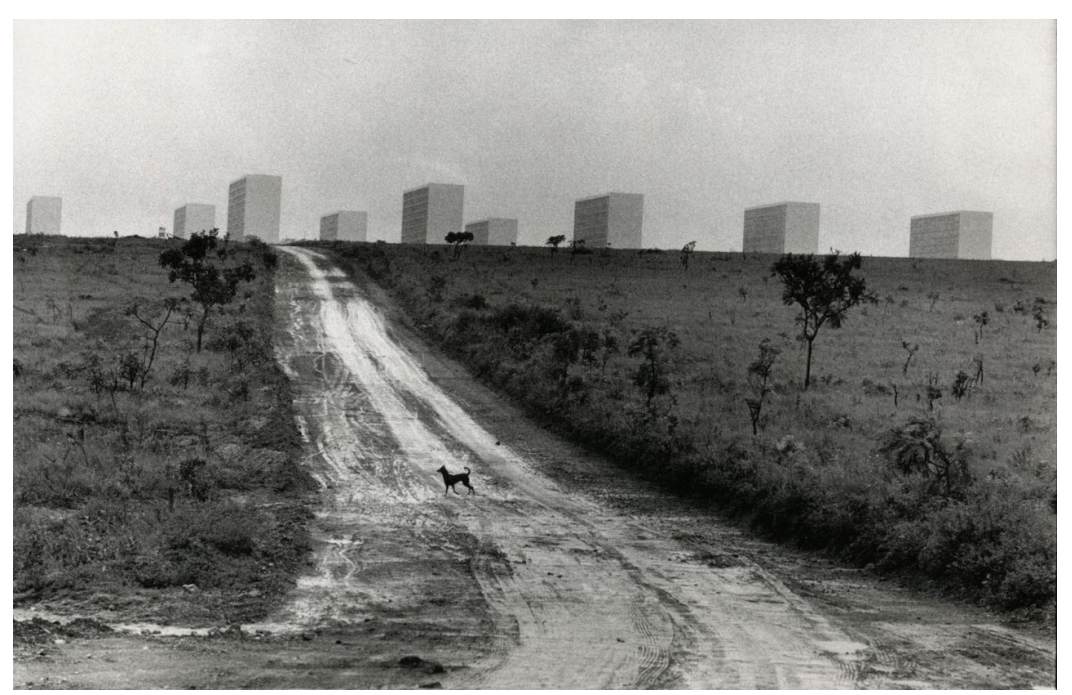

Erwitt/Magnum, Un punto de vista, 1968 


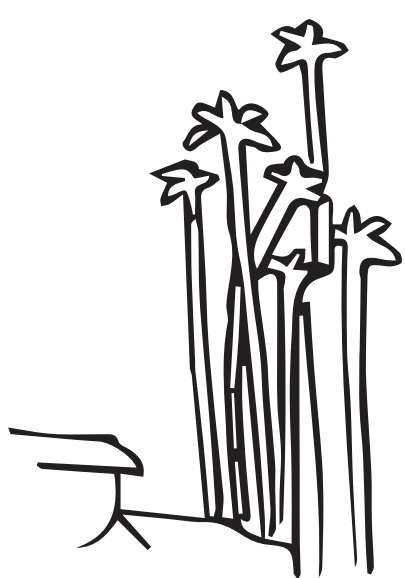

Este libro fue compuesto en fontes Literata e Work Sans en octubre de 2021. 